\title{
Assessment in Higher Education: A Critical Review of a Masters-Level Module's Assessment Procedures
}

\author{
Hamza Alshenqeeti ${ }^{1^{*}}$ \\ ${ }^{1}$ Taibah University, Madinah, Saudi Arabia.
}

Author's contribution

The sole author designed, analysed, interpreted and prepared the manuscript.

Article Information

Editor(s):
(1) Suleyman Goksoy, University of Duzce, Turkey.
Reviewers:

(1) P Moodley, South Africa.

(2) Gustavo A. Casañ, Jaume I University, Spain.

Complete Peer review History: http://www.sdiarticle4.com/review-history/55242

Short Research Article

Received 09 January 2020

Accepted 16 March 2020

Published 24 March 2020

\begin{abstract}
This paper presents a brief evaluation of a Masters-level module taught in a number of UK universities within language and linguistics departments. It will illuminate the underlying rationale for the module's assessment procedures in assessing students' learning; aiming not only for description and explanation, but for evaluation. Furthermore, in connection with assessment literature, issues of validity and reliability of the module's assessment will also be discussed. To end with, suggestions which may improve the assessment procedures of the module under study will be presented, before a conclusion is drawn up.
\end{abstract}

Keywords: Assessment; formative assessment; reliability; summative assessment; validity.

\section{INTRODUCTION}

Assessment is an integral element in the overall process of teaching and learning. According to Race [1], assessment is the 'principal driving force for learning' (p. 39). Hence, A considerable amount of research studies (e.g. Boud [2]; Shepard [3]; Yorke [4]; Webb and Jones [5]; Carless [6]) has been carried out to investigate and promote the role of assessment in the teaching/learning process. As noted by Barkley and Major [7], assessment in higher education is

*Corresponding author: E-mail: hshenqeeti@taibahu.edu.sa; 
different from that in other educational settings. This is partly due to the fact that higher education as a context is not only different, but is even more complex. More specifically, I would put it in Gibbs and Simpson's [8] words:

"when teaching in higher education hits the headlines, it is nearly always about assessment: about examples of supposedly falling standards, about unreliable marking or rogue external examiners, about errors in exam papers, and so on...Where institutional learning and teaching strategies focus on assessment, they are nearly always about aligning learning outcomes with assessment and about specifying assessment criteria ...[...]" (p. 29).

Hence, as Fry et al. [9] point out, a key subject matter in contemporary higher education is constructing assessment practices in a way that maximises opportunities for students' 'meaningful' learning. However, this alignment of assessment with the teaching/learning process is still a matter of debate in higher education research. That is, as reported in various studies (e.g. Heywood [10]; Gourley [11]), students' engagement with a study unit is, to a large degree, based on their expectations of how they will be assessed. In addition, despite its wellestablished research, assessment suffers from several major drawbacks in practice. Therefore, a review of the assessment in a higher education context is needed as it may further illuminate the issue under consideration.

Following this introduction is a brief literature review, which firstly discusses the role of assessment in higher education, and then discusses the types of assessment. Besides, in order to manifestly draw upon this, an attempt will be made to critically evaluate the assessment procedures of a Master's degree (MA hereafter) module that is taught in a number of UK, and more recently non-UK, universities.

\section{LITERATURE REVIEW}

"No academic exercise can be more useful than that of examination. It whets the desire for learning; it enhances the solicitude of study while it animates the attention of whatever is taught" (Madaus et al. [12]).

Apparently, despites the fact that they may carry different meanings, the terms 'examination' and 'assessment' are thought of as synonyms since they have frequently been used by researchers interchangeably (Carless [6]). Yet, the current paper uses assessment, in its broad sense, i.e. "...any method used to better understand the knowledge that a student has gained" (Angelo [13]). Barkley and Major [7], amongst other researchers and commentators, argue that an abundant research on assessment has led to the belief that assessment, as an ongoing process, aims not only at analysing students' performance, but understanding it.

Going further, however, Gourley [11] argues that good assessment does not just assess 'subjectspecific skills and knowledge'; it rather provides an ongoing measure of how well students are developing their learning in general. Yet, stemming mostly from pedagogical purposes, a dichotomy is frequently seen in assessment literature, in which two common types of assessment are used; these are namely: formative and summative assessment. Such a dichotomy is not only presented in how assessment is undertaken, but even how feedback is provided (Fry et al. [9]). In the pages that follow, a more detailed discussion of these types and their relevance to higher education, is presented.

\subsection{Formative Assessment}

Over the past few decades, an increasing awareness has been witnessed in higher education assessment literature towards shifting the focus of assessment from assessing 'knowledge' to assessing 'learning' (Bell and Cowie, [14]). As described by Nicol and Macfrlane-Dick [15], formative assessment is the form of assessment intended to generate feedback on performance with the intention of accelerating students learning and improvement on day-to-day basis.

Formative assessment, as Yorke [4] points out, can be (a) formal, which is normally undertaken by teachers with reference to a set of curricular assessment frameworks, e.g. module activities; or (b) informal, where assessment can be undertaken by anyone as it represents a reaction to performance that is not specifically stipulated in the curriculum or an assessment framework, e.g. peer observation (p. 490).

Unlike summative assessment, then, formative assessment which normally takes place throughout the semester, tends to create more opportunities for students to learn from the 
received feedback and thus improve their skills (Wakeford, [16]). Yet, despite its effectiveness in promoting leaning for students in many educational setting (Holroyd, [17]); this is highly determined by the quality of the feedback students receive (Butcher et al. [18]). In other words, as Nicol and Macfarlane-Dick [15] argue, good feedback should "...facilitate developing self-assessment, deliver to students information of high quality and encourage teacher and peer dialogue about learning" (p. 211).

\subsection{Summative Assessment}

By definition, this type of assessment embodies one of the primary purposes of assessment which is, according to Rust et al. [19], to judge and summarise the quality and characteristics of assessed students. Besides, research has shown that although accused of being a traditional assessment approach (cf. Sadler, [20]; Carless, [6]), summative assessment is still being frequently used by assessors as a means for grading and marking learners' performance according to the extent to which they have achieved knowledge. Furthermore, researchers (e.g. Madaus et al. [12]) add that the belief that summative assessment drives students' learning is still widespread, longstanding, and deeply held in higher education circles.

In summative assessment, grading usually takes place at the end of the semester, and this, many researchers (e.g. Carless [21]) claim, is one of its weaknesses as learners will not able to benefit from the feedback since it is only received at the end of the module. However, Ramsden [22] argues that the importance of such a form of assessment is that it yields a rich pedagogical information which would provide teachers with information about students' 'real' performance. Arguably, even with reserving the epistemological question of whether or not there is a 'real' representation, this might be evident in some contexts. Interestingly, furthermore, summative assessment may also act as a form of formative assessment in the case where students learn from their success or even failure (ibid).

To sum this up, I would argue that assessment is not an exact science; i.e. it is not usually effortless to come to a decision that a specific assessment type is better than the other. However, I would assert that assessment in higher education, be it formative or summative, should consider the issues of validity, reliability and fairness of the assessment procedure undertaken.

\section{METHODS}

The module discussed in this paper is called Language Teaching (abbreviated henceforth LT) and is taught at departments of language and linguistics at an MA level. The rationale behind opting for this module as our focus of attention here is mainly two-fold: first, being a compulsory module for a large number of MA students; secondly, amongst other MA modules, LT is more related not only to students' academic study, but to their future career (particularly for those who are/will be involved in teaching professions). Thus, before reviewing its assessment procedures, it is worth looking at LT content and aims as this will further enrich our discussion and authenticate our judgments.

\subsection{Module Content}

It is worth mentioning that of few other MA modules taught at MA level, LT is a core module for students in various MA programmes. This is due to the fact that it covers an extended array of applied linguistics and TESOL topics. Starting with an introductory (informal) lecture, the module is delivered on a weekly basis, i.e. $1 \times 2$ hour class per week over a period of 10 weeks. However, in order to fulfil the module's aims, students are asked to attend classes consistently, and do preparatory and follow-up reading as every session requires a familiarity with previously-discussed concepts.

\subsection{Module Aims and Learning Outcomes}

Broadly, the module is concerned with how language teaching methods and approaches are used and developed. Furthermore, it aims at familiarising students with basic applied linguistics concepts and underlying notions. By the end of the module, then, students are expected to:

- Be familiar with the development of theories and approaches to language teaching;

- $\mathrm{Be}$ able to examine the relationship between theory and practice in language teaching; and

- Explore recent thinking about key aspects of language teaching. 


\subsection{Module Assessment}

The assessment of the module is summative in nature; by this is meant that is, to evaluate students' understanding and ability to undertake an independent piece of scholarly research on a specific topic, students are asked to submit a 3000-word essay on one of a wide range of topics that are set previously by the teacher. Topics revolve mainly around the areas of applied linguistics and TESOL. The essay is to be submitted at least four weeks after the end of the module sessions and all essays are tutormarked by a couple of experienced markers. In marking students work, raters use the department's unified marking scale.

\section{RESULTS AND DISCUSSION}

\subsection{Critical Evaluation}

As reported by Black and William [23], about $80 \%$ of British higher education institutions depend on written assessment, e.g. tutor-marked essays and reports. More comparable to these findings, Carless [21] mentioned that most of the studies on assessment in higher education contexts found that tutor-marked essays are a key element of both coursework and exams in numerous subject areas in UK universities. Arguably, however, the rationale behind this (and in our case as well) is to allow for student individuality and make them feel a sense of ownership towards their learning. Besides their demonstration of students understanding, essays also involve learning by doing (Race [1]). Furthermore, assessment using essays may help maintaining a key aim of higher education, which is as Walsh and O'Keeffe [24] describe, 'fostering criticality and promoting individualised thinking'.

Irrespective of their pedagogical merits, however, essays can be fraught with various drawbacks. According to (Holroyd, [17]), besides being a traditional form of academic assessment, essays may cause a lack of equality as some students may never have been shown how to write essays well. Furthermore, essays can be timeconsuming not only for the students to plan, draft, and polish; but for the tutors who eventually mark them (Heywood [10]). Additionally, it can be argued that essays alone as a means of assessment, do not preclude markers' bias as with the use of the same marking scheme, multiple markers may give different marks for the same essay. That is to say, what is seen by a marker as an 'excellent' or 'valid' point or argument, might not be as such for another marker and vice-versa.

Notwithstanding these reservations, however, it can be claimed that although LT has been thought to have put a significant emphasis on promoting students understanding of a set of key concepts (at least from the researcher's standpoint), it still needs to put more emphasis on the assessment practices undertaken. By and large, hence, I would argue that although being a prevalent assessment method (cf. Race [1]), it does not mean that essays should not go hand in hand with other assessment tools, e.g. portfolios.

In other words, developing an assessment framework that would further give feedback to students and develop their learning formatively (Boud [25]). In sum, then, although some researchers (e.g. Madaus et al. [12]) may argue that summative essays are beneficial in many ways; I would claim that there still several concerns concerning their validity and reliability: issues that any good assessment tool must secure in order to be used especially in serious pedagogical situations (Briggs et al. [26]).

\subsection{Assessment Validity}

One of the key factors in any form of assessment its validity: which is when an assessment tool measures what it is meant to measure (see Boud $[2,25])$. However, in summative essays, as in our case, attaining a high level of validity is difficult (Holroyd, [17]). That is, as students' performance can be well-developed through teacherfeedback; the feedback as experienced in LT was obtained quite late (i.e. two months after the end of the module). Although this might be a result of the time limitation, as it might be difficult for teachers to give and discuss the feedback with regard to the large numbers of students attending the module (i.e. from 30 to $50 \mathrm{MA}$ students per university), it still even threatens the feasibility of using summative essays.

Moreover, summative essays may lead to what Weir [27] calls 'consequential validity', which is the effect of the score interpretations on the students. However, from my own experience, although it was not detailed enough, the interpretation of the assessment scores (see Appendix 2) was clear. Yet, I still agree with Holroyd [17], and thus cautiously argue that using essays as a summative assessment device makes it difficult to know what exactly is being measured. 


\subsection{Assessment Reliability}

As simply defined by Weir [27] reliability is the "consistency of measures across different times" (p. 24). Therefore, an assessment tool cannot be reliable unless it yields dependable results for the same performance across successive administration. With regard to LT's assessment, the different understandings of the assessment (i.e. anticipations concerning the essay), students might get misled and thus over-perform or even the opposite (Briggs et al. [26]). Besides, in my opinion, without the teacher's feedback, the marking scale used in LT was not sufficient (i.e. it had few criterion-descriptors). In sum, as reported in various studies (e.g. Nightingale et al. [28]; Yorke [4]), it is difficult to maintain the reliability of university-level essays as they may have a wide margin of variation not only in their implementation, but in their marking and grading.

\subsection{Suggestions for Improvement}

Certainly, assessment, as a continuous and active procedure, needs to be improved. Hence, innovation in learning tools and practices for assessment purposes is a growing trend among researchers and educators (Webb and Jones [5]). In this penultimate section, therefore, a number of suggestions are presented in an attempt to improve the assessment of the module under investigation.

(1) It would be beneficial to include a formative assessment task, e.g. student presentation, as part of the module's assessment. This would help students to learn from the teacher's feedback (Yorke, [4]) and thus develop their performance.

(2) It may also be useful to allocate less weight for the essay, e.g. $60 \%$, and allocate the remaining mark for another assessment tool. Furthermore, it may also worth given students more choices in choosing the topics of their essays rather than limiting them to a limited set of choices.

(3) To avoid misleading students, the teacher should explain the assessment criteria for students right at the beginning of the module. This is because students' understanding of the assessment criteria would further improve their performance and cautiousness.

(4) It is worth following Falchikov [29] who argues that student self-assessment may significantly improve learning, and this improvement may last over time. Thus, I recommend that this type of assessment should be formatively integrated in LT as it would help students develop a pragmatic rationale that would help them do better in their summative assessment task (Carless, [21]).

\section{CONCLUSION}

To conclude, then, the current paper calls for prioritising the inclusion of more than one method of assessment in the module under study. This is to avoid what (Race [1]) refers to as turning students into 'essay producing machines' or even 'examination junkies' (p. 47). Yet, as Webb and Jones [5] argue, when choosing assessment items we tend to stay with the known or the 'tried and true methods' (p. 170), because they seem to have the ring of academic respectability, or possibly because it was the way we were assessed ourselves.

Accordingly, it might be unjust to accuse teachers who solely use essays, of neglecting multi-method assessment or overcoming its value. Yet, when choosing assessment methods, they should "... have one eye on the immediate task of assessing student learning in a particular unit of study, and another eye on the broader aims of the programme and the qualities of the graduating student" (Race [1]) (p. 86).

Hence, I would only add that this can be done using a planned assessment strategy across the whole module. That is, with small step changes in assessment procedures, Shepard [3] remarks, would result in a big change in students' learning. In a word, therefore, if there is a wish (and there should be), to enhance student learning, then assessment methods in higher education contexts should at least be evaluated from time to time, reformed and improved continuously. By so doing, teachers and educators will have the "tools they need to succeed and excel in today's increasingly complex teaching and learning environment" (Barkley and Major, [7] (p. 30)).

\section{COMPETING INTERESTS}

Author has declared that no competing interests exist.

\section{REFERENCES}

1. Race P. The Lecturer's Toolkit. ( $3^{\text {rd }}$ Ed.). London: Routledge; 2006. 
2. Boud D. Assessment and learning: Contradictory or complementary. Assessment for Learning in Higher Education. London: Kogan Page; 1995.

3. Shepard L. The role of assessment in a learning culture. Educational Researcher. 2000;29(7):4-14.

4. Yorke M. Formative assessment in higher education: Moves towards theory and the enhancement of pedagogic practice. Higher Education. 2003;45(4):477-501.

5. Webb M, Jones J. Exploring tensions in developing assessment for learning. Assessment in Education: Principles, Policy and Practice. 2009;16(2):165-184.

6. Carless D. Excellence in university assessment. London: Routledge; 2015.

7. Barkley EF, Major $\mathrm{CH}$. Learning assessment techniques: $A$ handbook for college faculty. USA: Jossey-Bass; 2016.

8. Gibbs G, Simpson C. Conditions under which assessment supports students learning. Learning and Teaching in Higher Education. 2004;1: 3-31. [Online]

Available:http://www.glos.ac.uk/department s/ clt/lathe/issue1/index.cfm

(Accessed: 08 April, 2019)

9. Fry $\mathrm{H}$, Ketteridge S, Marshall S, (Eds.). A handbook for teaching and learning in higher education. ( $\left.{ }^{\text {rd }} \mathrm{Ed}\right)$. London: Sterling; 2008.

10. Heywood J. Assessment in higher education: Student learning, teaching, programmes and institutions. London: J. Kingsley; 2000.

11. Gourley W. Conceptualising the interface between English further and higher education. Unpublished Doctoral Thesis, The University of Sheffield, UK; 2010.

12. Madaus G, Russell M, Higgins J. The paradoxes of high stakes testing. Charlotte: Information Age Publishing; 2009.

13. Angelo TA. Reassessing and defining assessment. The AAHE Bulletin. 1995;48(2):7-9.

14. Bell B, Cowie B. The characteristics of formative assessment in science education. Science Education. 2001;85: 536-553.

15. Nicol DJ, Macfarlane-Dick D. Formative assessment and self-regulated learning: A model and seven principles of good feedback practice. Studies in Higher Education. 2006;31(2):199-218.
16. Wakeford R. Principles of student assessment, in Fry $\mathrm{H}$, Ketteridge $\mathrm{S}$, Marshall S, (Eds.). A Handbook for Teaching and Learning in Higher Education. London: Sterling; 2003

17. Holroyd C. Changing assessment in higher education: Policy, practice and professionalism. Unpublished Doctoral Thesis, The Institute of Education, The University of Stirling, UK; 2003.

18. Butcher C, Davies C, Highton $M$. Designing learning. London: Routledge; 2006.

19. Rust C, Price M, O'Donovan B. Improving students' learning by developing their understanding of assessment criteria and processes. Assessment \& Evaluation in Higher Education. 2003;28(2):147-164.

20. Sadler DR. Formative assessment: Revisiting the territory. Assessment in Education: Principles, Policy \& Practice. 1998;5(1):77-84.

21. Carless D. Prospects for the implementation of assessment for learning. Assessment in Education: Principles, Policy \& Practice. 2005;12(1):39-54.

22. Ramsden $P$. Learning to teach in higher education. ( $\left.2^{\text {nd }} E d.\right)$. London: Routledge; 2003.

23. Black P, William D. Assessment and classroom learning. Assessment in Education. 1998;5(1):7-74.

24. Walsh S, O'Keeffe A. Investigating higher education seminar talk. Novitas Royal. 2010;4(2):141-158. [Online]

Available:http://www.novitasroyal.org/Vol_ 4_2/walsh_okeeffe.pdf (Accessed: $12^{\text {th }}$ April, 2019)

25. Boud D. Sustainable assessment: Rethinking assessment for the learning society. Studies in Continuing Education. 2000;22(2):151-167.

26. Briggs J, Tang $\mathrm{C}$, (Eds.). Teaching for quality learning at University. Buckingham: Society for research into higher education and Open University Press; 2007.

27. Weir CJ. Language testing and validation. London: Pelgrave; 2005.

28. Nightingale $\mathrm{P}$, Te Wiata IT, Toohey $\mathrm{S}$, Ryan G, Hughes C, Magin D. Assessing Learning in Universities Professional Development Centre. Sydney: University of New South Wales Press; 1996.

29. Falchikov N. Improving assessment through student involvement. London: Routledge; 2005. 


\section{APPENDICES}

\section{APPENDIX 1}

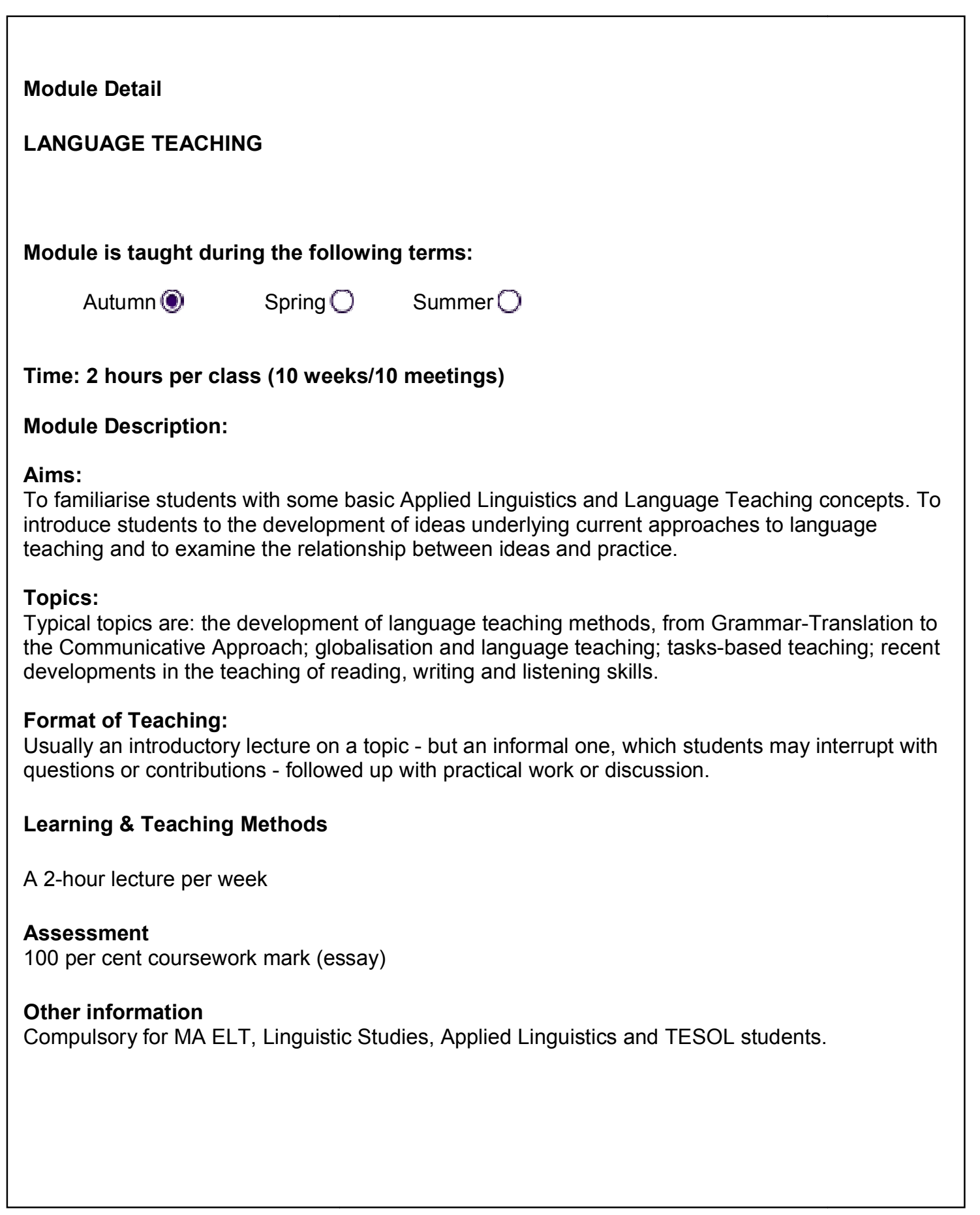




\section{APPENDIX 2}

Marking scale for graduate work at most UK departments of language and linguistics.

\begin{tabular}{lll}
\hline Class & Mark & Performance on tested outcomes \\
\hline Distinction & 70 or more & $\begin{array}{l}\text { very good or better on (almost) all tested outcomes and good on any } \\
\text { others }\end{array}$ \\
Merit & $60-69$ & $\begin{array}{l}\text { good or better on (almost) all tested outcomes and fair on any others } \\
\text { satisfactory or better on (almost) all tested outcomes. }\end{array}$ \\
Pass & $50-59$ & unsatisfactory on a significant number of tested outcomes. \\
\hline Fote: Marks above 80 are only awarded for demanding work of truly exceptional standard \\
\hline
\end{tabular}

APPENDIX 3

Examples of the questions/topics used in the assessment are:

- Discuss the positive and negative effects of Globalisation on Language Teaching and examine how and why Globalisation can be resisted by adopting a methodology that is appropriate to the context in which it is used, referring in particular to a context you are familiar with

- Examine an EFL course-book published in your context. What beliefs about language and about language learning underlie the design of this teaching material. Describe a sample of tasks, topics and activities with mentioning the expected roles of learners and teachers. Estimate how far the approach to teaching corresponds with any of the methods or approaches studied during the module (Language Teaching). Giving reasons, suggest any modifications that you might want to make to the course-book to make it more effective in your context.

(c) 2020 Alshenqeeti; This is an Open Access article distributed under the terms of the Creative Commons Attribution License (http://creativecommons.org/licenses/by/4.0), which permits unrestricted use, distribution, and reproduction in any medium, provided the original work is properly cited.

Peer-review history:

The peer review history for this paper can be accessed here: http://www. sdiarticle4.com/review-history/55242 